\title{
O GROTESCO MEDIEVAL: HYERONIMUS BOSCH E AS CANTIGAS DE MALDIZER PORTUGUESAS
}

\author{
*Rogério Caetano de Almeida
}

\section{RESUMO}

Este trabalho aborda a teoria do realismo grotesco de Mikhail Bakhtin aplicado em manifestações artísticas diferentes (a pintura de Hyeronimus Bosch e as cantigas de maldizer portuguesas). O ensinamento do estudioso russo mostra um "mundo às avessas" possível dentro da realidade artística - poesia e pintura neste caso. Outro fator a ser observado é a similaridade das manifestações de arte medievais descritas com realizações artísticas múltiplas de nossa contemporaneidade.

Palavras-chave: Realismo grotesco. Cantigas de maldizer. Hyeronimus Bosch.

\section{ABSTRACT}

This work approaches the theory of the grotesque realism of Mikhail Bakhtin applied in different artistic manifestations (the Hyeronimus Bosch's painting and Portuguese imprecate poems). The teaching of the Russian shows a "reverse world" possible inside of the artistic reality, poetry and painting. Another point to be observed is the similarity of the, here described, medieval artistic manifestation with the occured multiple artistic accomplishments in our contemporary time.

Key words: Grotesque realism. Imprecate poems. Hyeronimus Bosch.

* Doutorando na área de Literatura Portuguesa pelo Departamento de Letras Clássicas e Vernáculas da Faculdade de Filosofia, Letras e Ciências Humanas da USP. Mestre em Estudos Comparados de Literaturas de Língua Portuguesa da FFLCH-USP. 


\section{O REALISMO GROTESCO}

Quando Mikhail Bakhtin escreveu seu livro A Cultura Popular na Idade Média e no Renascimento, o contexto de François Rabelais, elaborou uma teoria sobre a literatura carnavalizada, ou grotesca (um termo que o autor discorda). Esse estudo foi baseado na obra de François Rabelais e a sua escrita com origem nas festas populares, que deixaram marcas profundas na cultura medieval europeia e permaneceu até o século XVIII.

Todavia, o crítico desenvolveu sua teoria e aplicou-a somente ao âmbito literário - entre outros, a Gargantua e Pantagruel, de Rabelais. A ideia de nosso trabalho é verificar a adequabilidade de sua teoria em um período contemporâneo e analisar a pintura de Hyeronimus Bosch. Além disso, verificaremos se suas teorias são aplicáveis também nas cantigas de maldizer portuguesas que são anteriores a Rabelais e Bosch.

Assim, o trabalho visa desenvolver uma pesquisa sobre o realismo grotesco (corporal) nas cantigas de maldizer portuguesas medievais e identificar os mesmos traços grotescos nas obras do pintor holandês Hyeronimus Bosch. Para completar o estudo, utilizaremos os estudos sobre o grotesco feitos por Victor Hugo e Wolgang Kaiser. Por fim, verificaremos a aplicação destas teorias nas cantigas de maldizer e nos quadros de Hyeronimus Bosch identificando suas semelhanças e diferenças.

\section{O GROTESCO MEDIEVAL: HYERONIMUS BOSCH E AS CANTIGAS DE MALDIZER}

Ao estudarmos a arte medieval, fica-nos uma pergunta: por que o descaso com período tão rico? Talvez tenha origem em um velho chavão: "a Idade Média é a Idade das Trevas". Porém, ao observarmos a inventividade da arte na época, concluímos que todas as prerrogativas são infundadas. Além disso, não podemos nos esquecer de que as cantigas de maldizer fazem parte de nossa origem literária:

A influência é simplesmente uma transferência de personalidade, uma maneira de entregar a outro o que se tem de mais precioso; seu exercício produz uma sensação e talvez mesmo a realidade de uma perda. Todo discípulo se apodera de alguma coisa de seu mestre (BLOOM, I99I, p. 34).
As cantigas de maldizer surgem na Baixa Idade Média como uma cultura alternativa à oficial que era controlada e manipulada pela Igreja. Elas possuem formato parodístico e têm por objetivo a sátira mordaz à sociedade, mostrando os vícios de políticos, padres e classes privilegiadas de forma a rebaixá-las e todas elas possuem uma conotação sexual. Não podemos deixar de observar que as cantigas satíricas medievais são "cantadas" em eventos realizados na praça pública, possuindo, portanto, uma forte influência popular. Exigiam uma performance dos trovadores e daqueles que participavam da execução das cantigas - o povo.

Outra característica importante é a relação da sátira com os rituais carnavalescos medievais que possuíam um caráter de destronação dos valores morais, sociais e religiosos que acabavam por construir a ordem social. O mundo oficial morria para o nascimento de uma nova realidade. Ao contrário das literaturas grotescas do século XIX e contemporânea, a medieval é ácida em seus ataques aos maus costumes com um caráter que Bakhtin chama de ambivalente. A ambivalência constitui um discurso destruidor que degrada e mortifica o criticado, porém juntamente com esses aspectos, regeneravam e renovavam. Assim, temos:

No realismo grotesco, o elemento material e corporal é um princípio profundamente positivo, que nem aparece sob uma forma egoísta, nem separado dos demais aspectos da vida. O princípio material e corporal é percebido como universal e popular, e como tal opõe-se a toda separação das raízes materiais e corporais do mundo, a todo isolamento e confinamento em si mesmo, a todo caráter abstrato, a toda pretensão de significação destacada e independente da terra e do corpo. O corpo e a vida corporal adquirem simultaneamente um caráter cósmico e universal; não se trata do corpo e da fisiologia no sentido restrito e determinado que têm em nossa época; ainda não estão completamente singularizados nem separados do resto do mundo (BAKHTIN, I999, p. I7).

Observando os comentários, temos uma totalidade dentro do universo carnavalesco-grotesco medieval. Contrapondo-se com os ideais individualistas que surgem no século XIX e perduram até hoje, percebemos a ambivalência como 
uma força potencializadora que, ao mesmo tempo critica o outro e retorna sobre si mesma. Essa crítica não é feita a um indivíduo ou outro especificamente, mas ao generalizado, e aquele que critica não possui uma voz, mas representa uma voz-coletividade. Além disso, a destruição que é causada pela sátira renasce através do riso que age em caráter positivo. $\mathrm{O}$ intuito da sátira medieval (realismo grotesco) é criticar e destruir, e definitivamente rir do que foi criticado. O riso é a grande finalidade desse tipo de manifestação e ele ocorre da mesma maneira como foi a Idade Média, "uma grande realização coletiva", segundo Segismundo Spina.

No que diz respeito ao corpo grotesco, Bakhtin (I999, p. 320) diz que esse corpo é "universal e reúne todos os elementos: animal, vegetal e humano; ele é inacabado e aberto (sic)". Justamente por esse corpo ser inacabado, ele se torna animado, como todas as outras coisas, portanto, esse corpo é, também, parte do universo:

todos os fenômenos e coisas do mundo - desde os astros até aos elementos - abandonaram seu antigo lugar na hierarquia do universo e dirigiram-se para a superfície horizontal única do mundo em estado de devir, encontraram novos lugares para si, ataram novos laços, criaram novas vizinhanças. E o centro a cuja volta se efetuou esse reagrupamento de todos os fenômenos, coisas e valores, era o corpo humano, que reunia no seu seio a imensa diversidade do universo (BAKHTIN, I999, p. 320).

Assim, veremos como se dá a construção do corpo grotesco nas cantigas de maldizer:

Cantiga n. I29 no livro de Rodrigues Lapa:

Nenguen-min, que vistes mal doente

De mao mal, ond' ouver' a morrer,

Eu puj' a mão en el, e caente

$\mathrm{O}$ achei muit', e mandei-lhi fazer

Mui boa cama, e adormeceu;

E espertou-s' e cobriu-s' e peeu,

E or [a] já mais guarido se sente.

Achei-o eu jazer desacordado,

Que non cuidei que podesse guarir;
E, pois eu vi que era mal coitado, Mandei-o benn caentar e cobrir; E, des que s'el bem coberto sentiu, Estornudou tres peidos e guariu Já quanto mais, e é mais arriçado.

Achei-o eu mal doente, u jazia Desacordado todo com o mal; E non cuidava que guareceria; Mias a mercee de Deus quanto val! Que, u sa gente d' el desasperou, Feriu tres peidos e determinhou E conhoceu, ca já non conhocia.

Deste mal non cuidei que guarecesse, Pero mandei-lhe fazer ua ren:

Que aquel dia per ren non comesse

E se deitasse e se cobrisse bem; E el deitou-se e cobriu-s' enton, E peeu bem e ouvve coraçon Pois se bever, e dix' eu que bevesse.

A tradução interpretativa do texto é:

O trovador faz de físico, e aplica o seu fingido saber a um tal Nenguem-mim, talvez um seu jogral, que teria salvo de uma doença grave, quando já ninguém dava nada por ele. O autor insiste grotescamente no alívio dos gases intestinais, com aquele peer e locuções sinônimas, e remata, segundo parece, numa alusão ao vício da bebedice, que é onde quererá chegar (LAPA, I965, p. 208-209).

Como podemos perceber, Rodrigues Lapa era um profundo conhecedor do aspecto popular que as cantigas possuíam. Esta cantiga possui, talvez, todos os elementos do realismo grotesco. Vejamos: começa com um homem de possível nome paródico prestes a morrer de alguma doença. Mas o trovador (Fernan Garcia Esgaravunha - nome paródico em si) tentará de todas as formas reanimá-lo. O homem queimava em febre ("e caente o achei muito"), mas os cuidados que o amigo toma são fundamentais para salvá-lo. Arruma uma boa cama para que este possa sarar. O doente, em seguida, dormirá bastante e será bem coberto. De repente, o doente começa a peidar (para que o texto não perca intensidade, devemos utilizar a palavra fielmente), logo começa a 
melhorar. O amigo, observando a melhora do doente, encontra-o desacordado e não acredita em uma melhora, acha-o quase morto (mal-coitado). Neste momento começa a grande reação para a vida do doente. Ele espirra três peidos e começa a se sentir mais animado.

$\mathrm{Na}$ terceira estrofe do poema, o trovador pede a ajuda de Deus para que o doente se salve. De repente, escuta mais três peidos e pouco tempo depois o corpo do doente resolveu viver. Na quarta estrofe, percebemos o final carnavalesco por excelência: o doente diz ao amigo ter vontade de beber. $\mathrm{O}$ amigo, feliz por ver o outro recuperado, diz que é para beber.

Os gases, como diz Bakhtin, são, juntamente com o escremento e a urina, matéria cósmica do universo do baixo material e corporal. A situação que temos neste poema é tipicamente carnavalesca. O doente está quase morto, mas o baixo material corporal faz com que ele torne à vida. Podemos perceber, também, que em uma das sequências de peido do doente, ele espirra peido, e, esse espirro, que originalmente sai da boca, é ligado ao baixo topográfico corporal: "a boca é a porta aberta que conduz ao baixo, aos infernos corporais. A imagem da absorção e da deglutição, imagem ambivalente muito antiga da morte e da destruição, está ligada à grande boca escancarada" (BAKHTIN, I999, p. 284).

Além do espirro, temos o peido que é parte do "inferno" corporal, ou seja, o baixo. Esse baixo é a ligação do universo corporal com a terra, com a fertilidade, com o novo. Assim sendo, representa uma transgressão da realidade oficial e demonstra que esses homens (o doente e o amigo) estão vivendo outra realidade - paródica e carnavalizada. Além disso, como diz Bakhtin, o peido é o sinal de ressurreição. O mundo às avessas possui um homem doente que só sara quando tem uma relação do mundo interior dele com o exterior que ressurge novo. Portanto, esse homem torna-se universal, ele morreu-viveu, degenerou-renovou, e termina o poema com o gesto clássico do Pantagruel rabelaisiano: pedindo uma bebida.

Cantiga n. I4 no livro de Rodrigues Lapa:

Fui eu poer a mão noutro di-

A a ua soldadeira no covon,

E disse-m'ela: - Tol-te, arloton,

Ca non é est'a [ ora d'alguen mi

Fornigar, u prendeu] Nostro Senhor
Paixon, mais é-xe de min, pecador, Por muito mal que me lh'eu mereci.

U a vós começastes, entendi

Bem que non era de Deus aquel son, Ca os pontos del no meu coraçon Se ficaron, de guisa que logu'i Guidei morrer, e dix'assi: - Senhor, Me fazes deste marteiro par ti!

Quisera-m'eu fogir logo dali, E non vos fora mui[to] sem razon, Com medo de morrer e com al non, Mais non púdi - tan gran coita sofri; E dixe logu'enton: - Deus, meu Senhor, Esta paixon sofro por teu amor, Pola tua que sofresti por min.

Nunca, dê-lo dia en que nasci, Fui tan coitada, se Deus me perdon; E com pavor, aquesta oraçon Comecei logo e dixe a Deus assi:

- Fel e azedo bevisti, Senhor,

Por min, mais mui'est'aquesto peior Que por ti bevo nen que recebi.

E poren, ai, Jesus Cristo, Senhor, En juizo, quando ate ti for, Nembre-chésto por ti padeci!

A análise de Rodrigues Lapa é a seguinte:

Cantiga de extraordinário atrevimento de idéias. Toda ela, a partir do v. 3 , é posta na boca duma soldadeira, que nos dá conta do remorso de ser acometida em dia de Paixão e, ao mesmo tempo, do martírio que padeceu em sua carne de não levar o fornízio ao fim, paixão só comparável, e ainda maior, à que padeceu o Cristo na cruz. O interesse psicológico da poesia está naquela vacilação que move a soldadeira entre os espinhos da consciência e as delícias do pecado - tudo envolvido numa teia de ironias, que dão a medida da liberdade existente em matéria de religião. A primeira estrofe está muito deteriorada nos códices e carecida de um verso, que reconstituímos, em leitura conjectural (LAPA, I965, p. 23). 
Segundo Lapa, percebemos um tom de louvor a Deus na fala da soldadeira (nos versos I2-I3: "Senhor, me fazes deste marteiro par ti"; e no verso I8: "Deus, meu Senhor"), porém, a fala de louvor é por esta mulher não poder fornicar no dia da paixão de Cristo. Para a época, o feriado era sagrado e a igreja procurava incutir nas pessoas uma postura de rejeição ao corpo. O trovador, muito jocoso e atrevido chega colocando a mão na "covon" ("cova") dela. A soldadeira pede para que o salafrário tire a mão de lá e logo em seguida invoca a Deus. Porém, na segunda estrofe, o trovador escuta um barulho de ressoar seu coração (Lapa supõe que seja o barulho do coito). Após o ato consumado, temos um louvor da soldadeira que diz "Senhor, bendito sejas tu, que sofredora me fazes deste martírio por ti” (tradução livre). Na terceira estrofe, ela se apaixona, e, somente por este motivo (coita) não foge dali. Daí por diante, temos uma sátira às cantigas de amigo, em que a dama sofre coita pelo amado que não volta e, na quinta estrofe, ela (a soldadeira) retoma o tema do sofrimento por Cristo. No final, sugere que padeceu por Cristo.

Percebemos nesta cantiga vários indícios de realismo grotesco. Primeiro o louvor, em tom jocoso, por se sacrificar somente pela fé. Seu sacrifício é fornicar com o trovador que lhe passa a mão na vagina. Temos o baixo material corporal que dá a luz ao novo (a vagina e o próprio ato sexual) e ao mesmo tempo um temor à realidade oficial que na verdade é jocoso, portanto, uma nova realidade é criada: o ato sexual como sacrifício para a mulher, poderia ser permitido no dia da paixão de Cristo. Com isso, temos a matéria risível na última estrofe quando ela diz ter somente por Ele padecido. Apenas a utilização de palavras mais ligadas ao popular, à feira, já demonstra que essa mulher não parece muito arrependida, o que torna seu sacrifício um grande prazer. O paraíso, para ela, é essa nova realidade que surge no momento da "fornicação", a dessacralização da norma e do ideal religioso através do ato sexual. É a morte da tradição religiosa oficial para o nascimento de algo novo, é a ambivalência que morre para nascer, que dessacraliza para sacralizar algo novo, o sexo como a representação do novo que surge, através do baixo material e corporal.

Quanto à vida e obra de Hyeronimus Bosch, as informações que possuímos são restritivas. Sabe-se que nasceu e viveu em uma pequena cidade belga do século XV, porém, identificam-se, em suas obras, ten- dências e temas medievais. Embasados em suas obras, estudiosos ainda não conseguiram definir quais foram os primeiros e os últimos quadros. Outro fato curioso é que enquanto o protestantismo se firmava em alguns países europeus, a arte desses lugares que se relacionava com o mundo católico era destruída. Conclui-se que muitos dos quadros de Bosch foram queimados, restando apenas trinta aos nossos dias. Supõe-se que sua atividade artística era intensa, pois casou-se com uma senhorita abastada de sua cidade.

Sobre o quadro As tentações de Santo Antônio, temos a seguinte nota esclarecedora:

A inspiração do quadro é conhecida: baseia-se na lenda de Santo Antônio. Depois de dar aos pobres o dinheiro que arrecada com a venda de seus bens, o santo se retira para uma fortaleza egípcia em ruínas no deserto a fim de meditar sobre as palavras do Cristo e levar uma existência piedosa. Logo, porém, os demônios - os pecados da vida pregressa - surgem para tentálo com visões lascivas ou apavorantes, pondo à prova a sua fé indômita e, no final, vencedora (GÊNIOS DA PINTURA, I973, p. I59).

Temos na obra um amálgama de motivos religiosos que foram trabalhados de forma que podemos observar o realismo grotesco. Para facilitar a análise, dividimos o quadro em seções. A primeira é aquela em que Santo Antônio e outros seres aparecem como que em uma missa. Outra seção importante, a nosso ver, é o canto direito inferior deste. Em destaque, no centro do quadro, temos Santo Antônio dentro da fortaleza em ruínas. No painel central, temos um padre de feições animalescas e seu sacristão é um ser de rosto monstruoso, com um funil invertido sobre sua cabeça. Segundo a orientação do livro, esse funil é símbolo da charlatanice. Atrás de Santo Antônio, "uma sacerdotisa coroada com uma mitra feita de serpentes oferece a hóstia a um músico de cabeça de porco sobre a qual pousa uma coruja. Ao lado, uma criada negra carrega num prato uma rã que ergue um ovo" (GÊNIOS DA PINTURA, I973, p. I77).

Antes de analisarmos o contexto, vamos à simbologia: a serpente, dentre vários significados, representa o animal que se mistura ao homem, rivaliza-se, opõe-se, complementa-se ao homem. O porco simboliza a voracidade, a gula. A coruja simboliza a inteligência, a clarividência e o conhecimento racional. 
A rã, no Ocidente, é considerada um símbolo de ressurreição. O ovo é o que contém o germe e a partir do qual se desenvolverá a manifestação - é um símbolo universal e explica-se por si mesmo.

Dentro do contexto, temos Santo Antônio dentro de um monastério em ruínas e às suas costas a sacerdotisa oferece a hóstia - purificação - ao guloso porco-músico que é o detentor do saber (a coruja) e carrega um cachorro com uma touca similar a de Arlequim. Logo atrás dele temos um deficiente corcunda. Um outro porco que identificamos no mesmo plano é o padre que lê a bíblia, talvez sua fome seja outra: a ganância, o poder, afinal seu sacristão representa a charlatanice. Ao fundo, temos uma igreja com um formato extremamente antropomorfizado - ela parece vestida de noiva. "Na parte inferior direita, uma mulher-árvore macilenta, de rosto azulado, cavalgando uma enorme ratazana, embala um feto enfaixado, precedida de um tonel-animal e de um alado personagem sem rosto" (GÊNIOS DA PINTURA, I973, p. I77).

Neste âmbito, temos uma total inversão da ordem natural do mundo. Há uma mescla de animais, seres indefinidos, vegetais e homens metamorfoseados. O corpo grotesco em toda a obra é disforme, ele cria uma nova realidade social, um novo mundo. Segundo Bakhtin, a ambivalência está em perdermos o mundo normal, ele morre - para a criação de uma nova (des)ordem social. Não há mais um corpo definido, padrão, não há uma regra. O que ocorre, na verdade, é uma transgressão da realidade, há uma reinvenção de um mundo fantástico, também característico dentro do universo grotesco.

Para Bakhtin,

dentre todos os traços do rosto humano, apenas a boca e o nariz (esse último como substituto do falo) desempenham um papel importante na imagem grotesca do corpo. As formas da cabeça, das orelhas, e também do nariz, só tomam caráter grotesco, quando se transformam em figuras de animais ou de coisas. Os olhos não têm nenhuma função. Eles exprimem a vida puramente individual, e de alguma forma interna, que tem a sua própria existência, a qual não conta para nada no grotesco. Esse só se interessa pelos olhos arregalados, pois interessa-se por tudo que sai, procura sair, ultrapassa o corpo, tudo o que procura escapar-lhe.(...) Como já o sublinhamos várias vezes, o corpo grotesco é um corpo em movimento. Ele jamais está pronto nem acabado: está sempre em estado de construção, de criação, e ele mesmo constrói outro corpo; além disso, esse corpo absorve o mundo e é absorvido por ele (BAKHTIN, I999, p. 276-277).

Ao analisarmos a citação de Bakhtin, percebemos que esta combina com o que vimos nas cantigas de maldizer, pois elas são despojadas, rebaixadoras, bufonas e denegridoras. Enquanto comparamos com o grotesco do quadro analisado de Hyeronimus Bosch, percebemos que há uma certa relação da construção do modelo grotesco, porém o procedimento é diferenciado. O quadro demonstra um certo desespero, uma angústia e até certo ponto uma atitude moralizante, afinal As tentações de Santo Antônio assustam um pecadorexpectador. Se pensarmos nesse intuito moralizante, a obra de Bosch joga o expectador para uma nova realidade infernal, assustadora, grotesca para que este não aja como um pecador. Assim, temos uma arte grotesca para moralizar, não para dessacralizar, como nas cantigas de maldizer portuguesas.

Se o procedimento do realismo grotesco é fazer com que o mundo morra e renasça de uma nova maneira, mais livre e risível, os quadros de Bosch possuem a intenção contrária. É como se o quadro avisasse o expectador que se ele realmente cometesse pecados, a outra vida seria infernal como aquelas imagens das telas. Assim, a construção de um mundo grotesco com intenção moralizadora, seria o inverso da realidade grotesca: possuía o intento de assustar as pessoas. A redenção de Santo Antônio viria somente quando ele, homem, se conscientizasse de todas as suas paixões carnais. A paixão é representada na tela pela predominância da cor vermelha, mas o vermelho também é:

universalmente considerado como o símbolo fundamental do princípio de vida, com sua força, seu poder e seu brilho, o vermelho cor de fogo e de sangue, possui, entretanto, a mesma ambivalência simbólica destes últimos, sem dúvida, em termos visuais, conforme seja claro ou escuro. O vermelho-claro [...] é diurno, macho, tônico, incitando à ação, lançando, como um sol, seu brilho sobre todas as coisas, com uma força imensa e irredutível. O verme- 
lho-escuro [...] é noturno, fêmea, secreto e, em última análise, centrípeto; representa não a expressão, mas o mistério da vida. Um seduz, encoraja, provoca é o vermelho das bandeiras, das insígnias, dos cartazes e embalagens publicitárias; o outro alerta, detém, incita à vigilância e, no limite, inquieta: é o vermelho dos sinais de trânsito, a lâmpada vermelha que proíbe a entrada num estúdio de cinema etc. (CHEVALIER, 200I, 944-945).

\section{CONSIDERAÇÕES FINAIS}

Quando analisamos a formação do cânone em qualquer manifestação artística, percebemos que essa se constrói sempre quando um determinado artista alcança o sublime dentro de uma estética ou manifestação específica. Sabemos, também, que o cânone é dinâmico e que às vezes um artista é descoberto como gênio muito tempo depois.

As cantigas de maldizer portuguesas são normalmente desprezadas pela crítica por serem "baixas", "desprezíveis", porém dentro da arte grotesca também há uma sublimação: "o real resulta da combinação bem natural de dois tipos, o sublime e o grotesco, que se cruzam no drama, como se cruzam na vida e na criação. Porque a verdadeira poesia, a poesia completa, está na harmonia dos contrários" (HUGO, 2002, p. 46).

Como identificar o sublime dentro de uma arte dita grotesca? As duas formas de manifestação são antagônicas e complementares. Assim, a arte grotesca é excluída do cânone, mas é necessária a este. Se não fosse o grotesco, o que se manifestaria como esdrúxulo ou ridículo? Não podemos esquecer que para existir o sublime, deve haver também o inferior a ele, ou seja, o esdrúxulo ou ridículo. Portanto, concluímos que o grotesco participa do cânone mesmo quando não pertence a ele. Sendo uma paródia a ele ou não.

O mesmo acontece com a obra de Hyeronimus Bosch, só que de forma mais evidente. Apesar de suas telas com motivos e características grotescas, há uma sublimação, uma busca pelo elevado. Suas telas influenciaram indiretamente Pieter Brueghel, assim como, no século XX, o Surrealismo e o Expressionismo. Isso acontece por um único motivo: há uma beleza elevada na destruição, no horroroso, no desconhecido.

Por fim, as manifestações artísticas da contem- poraneidade têm uma relação muito significativa com as artes medievais estudadas aqui. Entretanto, o realismo grotesco não está evidente apenas nas artes de nossa conturbada e não menos interessante Idade Média. O realismo grotesco está presente até mesmo na contemporaneidade, como estudos profícuos identificaram.

\section{REFERÊNCIAS BIBLIOGRÁFICAS}

BAKHTIN, M. A Cultura Popular na Idade Média e no Renascimento: o contexto de François Rabelais. Trad. Yara Frateschi. 4 ed. São Paulo-Brasília: Edunb-Hucitec, I999.

BLOOM, H. A Angústia da Influência: uma teoria da poesia. Trad. Arthur Nestrovski. Rio de Janeiro: Imago, I99I.

GAMPOS, A. de. Verso, Reverso, Controverso. 2 ed. São Paulo: Perspectiva, I988.

GHEVALIER, J. \& GHEERBRANT, A. Dicionário de Símbolos. Trad. Vera da Costa e Silva. I6 ed. Rio de Janeiro: José Olympio, 200 I.

GÊNIOS DA PINTURA. São Paulo: Abril, I973.

HUGO, V. Do Grotesco e do Sublime: tradução do prefácio de Cromwell. Trad. Célia Berrettini. 2 ed. São Paulo: Perspectiva, 2002.

KAISER, W. O Grotesco. Trad. J. Guinsburg. São Paulo: Perspectiva, I986.

LAPA, M. R. Cantigas de escarnho e de mal dizer dos cancioneiros medievais galego-portugueses. Coimbra: Editorial Galáxia, I965.

RABELAIS, F. Gargântua e Pantagruel. Trad. David Jardim Júnior. Belo Horizonte: Villa Rica, I99I, col. Grandes Obras da Literatura Universal.

SPINA, S. A Lírica Trovadoresca. São Paulo: Edusp, I996.

ZUMTHOR, P. A Letra e a Voz. Trad. Amálio Pinheiro e Jerusa Pires Ferreira. São Paulo: Cia. das Letras, 200 I. 